\title{
AMINO ACID STUDIES. II. PLASMA AMINO ACID RETENTION, AS EVIDENCE OF IMPAIRED LIVER FUNCTION. INVESTI- GATIONS IN CHILDREN WITH NEPHROSIS AND LIVER DISEASE ${ }^{1}$
}

\author{
By J. D. LYTTLE, E. GOETTSCH, D. M. GREELEY, W. M. GRIM, ANd P. DUNBAR \\ (From the Department of Pediatrics, College of Physicians and Surgeons, Columbia Univer- \\ sity, and the Babies Hospital, New York)
}

(Received for publication August 7, 1942)

Kirk (1) reviewed the literature concerning liver dysfunction in relation to amino acid metabolism following the ingestion of glycine or mixtures of amino acids, and, in addition, reported his own experiments. Using the nitrous acid method of Van Slyke, he determined the amino acid $\mathrm{N}$ concentration in plasma, before and after the ingestion of 25 grams of glycine, in patients with hepatitis, liver cirrhosis, and obstructive jaundice. He concluded that no definite reduction in the deamination of the amino acids was demonstrable in patients with liver disease and that the glycine tolerance test under the conditions of his experiments was not suitable for the diagnosis of liver dysfunction. He also studied the urinary excretion of amino acids before and after the ingestion of glycine and reported that essentially the same amino acid excretion was observed in normal individuals as in patients with liver disease. Kitamura (2) demonstrated a retention of plasma amino acids following an intravenous injection of certain amino acids in rabbits with livers damaged by chloroform and similar poisons. From the plasma amino acid curves obtained after the intravenous injection of glycine in patients with liver disease, Horejsi (3) stated that little information could be gained by such methods unless severe liver destruction was present. Weicker (4) studied the behavior of blood amino acid levels following the ingestion of a mixture of equal parts by weight of glycine, leucine, asparagine, and tyrosine. He found that in some of the patients with liver disease, the retention of whole blood amino acids persisted longer but that the maximum values obtained were not higher than those obtained in normal controls.

1 Aided by funds from the Emeny Gift and from the Williams-Waterman Fund of the Research Corporation.
Weech (5) found a progressive fall in the ability of the liver to excrete bilirubin, early in the course of a dog fed a protein deficient diet, and, at autopsy, in some dogs similarly fed, histological evidence of liver damage. Elman (6) confirmed and elaborated on these findings, presenting evidence that morphological damage paralleled liver dysfunction as determined by the excretion of iso-iodeikon. Since liver damage occurs in the hypoproteinemic dog, this experimental animal provided the basis for study in this laboratory (7) of the relation between liver impairment and the clearance of amino acids from the plasma. Retention $^{2}$ of plasma amino acids following an intravenous injection of casein hydrolysate was observed in the hypoproteinemic dog early in the course of deproteinization, as shown in Figure 1, and the plasma amino acid retention increased as hypoproteinemia advanced. Evidence that this behavior was probably caused by delay in the rate of deamination was cited.

In nephrosis, Farr and MacFadyen (8) found chronic hypoaminoacidemia and at times, with or without peritoneal infection, a sharp critical drop in the level of plasma amino acid. Also, in nephrosis, it is generally conceded that a defect in the synthesis of plasma protein exists.

The present paper reports investigations of the reactions of nephrotic children to injections of casein hydrolysate and the rate at which the material was metabolized. In addition, similar studies were carried out on patients with liver disease and normal renal function, and conversely, on patients with kidney disease and unimpaired liver function, in an attempt to evaluate if possible the

\footnotetext{
2 Retention will be used throughout the paper to connote increased plasma values of amino acid $\mathrm{N}$ above the highest value found in the controls at any time interval following the injection of casein hydrolysate.
} 


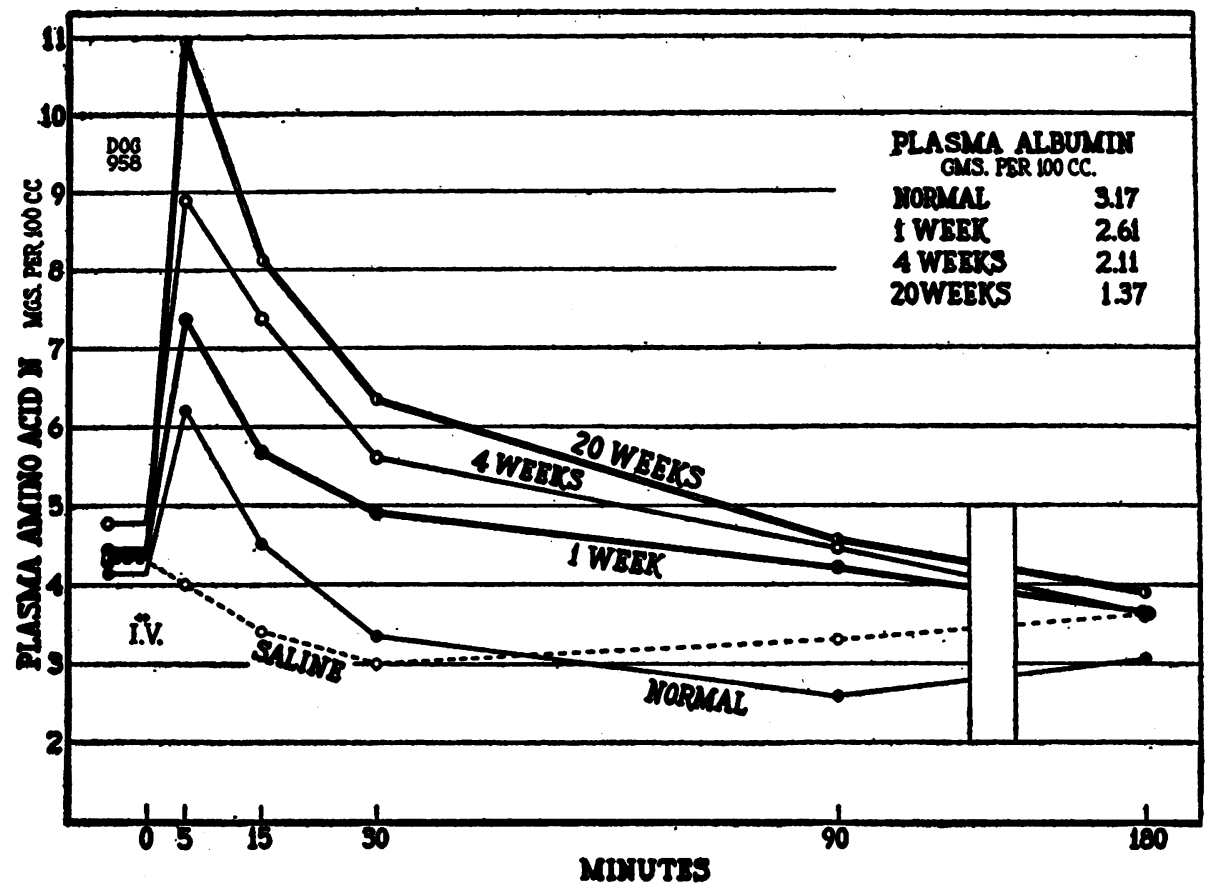

Fig. 1. The Progressive Retention of Plasma Amino Acid N After Intravenous Injections of Casein Hydrolysate in the Dog as Hypoproteinemia Progresses

The curve marked "normal" represents the reaction while on a normal diet. The curve marked "saline" represents the reaction to a control intravenous injection of 5 per cent glucose in saline, with a normal diet.

part played by each of these important organs in the deamination and disposition of amino acids.

\section{PROCEDURE}

Amino acid loading curves were carried out in normal controls and in the patients selected for study. In the earlier experiments on children 8 to 10 years of age, 40 cc. of 10 per cent solution of casein hydrolysate, ${ }^{8}$ diluted with 40 cc. of 5 per cent glucose in saline, were injected to fasting patients within 4 to 5 minutes. Later, when small children and infants were included, $2 \mathrm{cc}$. of the hydrolysate per kilo, diluted with an equal volume of 5 per cent glucose in saline, were given. This represented about $12 \mathrm{mgm}$. amino acid $\mathrm{N}$ per kilo of body weight, enough to raise the plasma amino acid $N$ level about $30 \mathrm{mgm}$. per $100 \mathrm{cc}$. if no amino acid were removed from the plasma. Blood samples were taken before and at 5 minutes, 15 minutes, 35 minutes, and 95 minutes after the completion of the injection. Urea $\mathrm{N}$ was determined on whole blood. The volume of packed red cells was measured and the plasma was analyzed for alpha amino acid $\mathrm{N} *$ and proteins. In addition, in some patients, the

${ }^{8}$ Kindly furnished by Mead Johnson and Company.

4 Throughout the paper, plasma amino acid $\mathrm{N}$ refers to alpha amino acid $\mathrm{N}$ as determined by the ninhydrin method. urinary excretion of end-products of the metabolism of casein hydrolysate, given intravenously, was studied. When possible, urine was collected so that one or more control periods were obtained before the intravenous injection and several periods thereafter. Catheterization was avoided so urine collections were not always obtained at the desired intervals. The urine was analyzed for $\operatorname{ammonia} \mathrm{N}$, amino acid $\mathrm{N}$, urea $\mathrm{N}$, protein $\mathrm{N}$, and total $\mathrm{N}$, and in some instances, the $\mathrm{pH}$ was determined by glass electrode. Methods have been previously described (7). From these data, the urea and amino acid clearances could be calculated.

\section{A. Plasma amino acid loading CURVes}

\section{Results in normal children}

The children selected as controls, being convalescent hospital patients, cannot be considered ideally normal but clinically they were free from obvious liver or renal disease. Casein hydrolysate was injected intravenously and the behavior of the plasma amino acids and blood urea was observed. The plasma amino acid loading curves in 9 normal children are shown in Figure 2 and the complete pertinent data from one of them are presented in Table I. As examination of the 
chart shows, wide variation of fasting levels of plasma amino acid $\mathrm{N}$ in these normal children was observed. The plasma amino acid $\mathrm{N}$ level reached the initial value 35 minutes after the injection in one third of the group, and in all of the controls, the preinjection value was reached in 95 minutes. In 2 of the controls, the final value fell below the preinjection level. This unexplained phenomenon had also been observed in normal dogs, Figure 1. Thus, no retention of amino acid was noted in any normal control 95 minutes after a load of intravenous amino acid. Blood urea levels remained essentially unchanged and shifts in hematocrit were slight, usually with a decrease immediately following the injection.

The average plasma amino acid $\mathrm{N}$ level in normal fasting individuals has been reported to be $4.5 \mathrm{mgm}$. per $100 \mathrm{cc}$. In a series of $31 \mathrm{de}-$
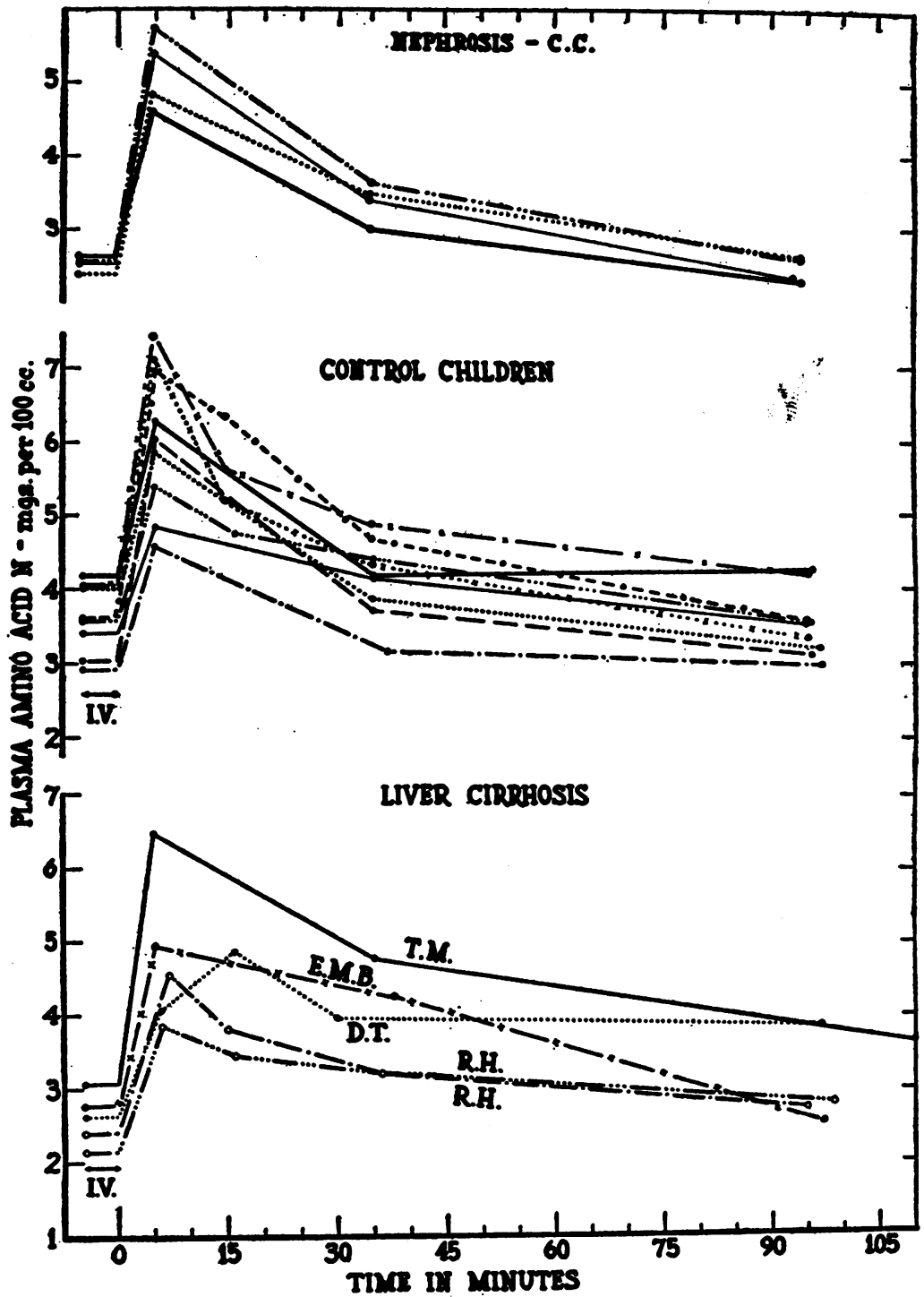

Fig. 2. Behavior of Plasma Amino Acid N Before and After the Injection of Casein Hydrolysate in Normal Chindren and in Patients with Nephrosis and Portal Cirrhosis

Retention becomes apparent if one places a guide line at the preinjection level for each curve. 


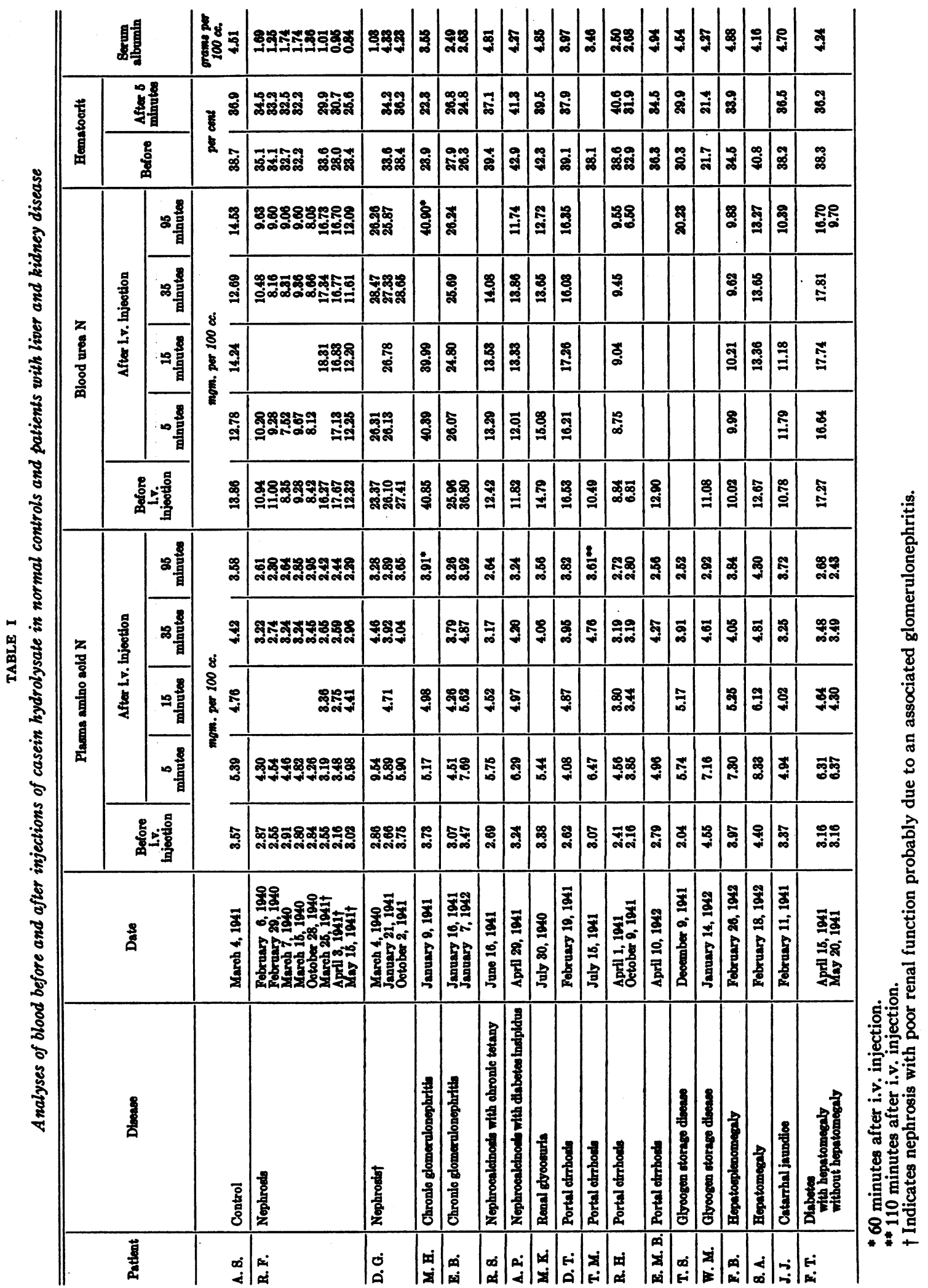


terminations in 30 normal adults and children, Farr, McCarthy, and Francis (9) stated that the plasma amino acid $\mathrm{N}$ values ranged from 3.75 to $5.56 \mathrm{mgm}$. per $100 \mathrm{cc}$. with a standard deviation of \pm 0.46 . In our hands, using the ninhydrin method of Van Slyke et al. (10), the values for 45 normal hospital children ranged from 2.92 to $4.63 \mathrm{mgm}$. per $100 \mathrm{cc}$. The mean was located at $3.60 \mathrm{mgm}$. per $100 \mathrm{cc}$.; the median at 3.53 , with quartiles at 3.24 and $3.92 \mathrm{mgm}$. per $100 \mathrm{cc}$.

\section{Results in patients with liver disease and good renal function}

Some support was given to the assumption that retention of plasma amino acids indicates liver injury, by studies on 4 patients with portal cirrhosis and unimpaired renal function. The clinical diagnosis was verified by microscopic examination of liver tissue, obtained either by biopsy or at necropsy. The amino acid loading curves in 3 of these patients, included in Figure 2, showed a significant delay in clearing the blood of amino acids after the injection of casein hydrolysate. In the fourth patient, E. M. B., studies carried out early in the course of the disease demonstrated considerable retention in $\mathbf{3 5}$ minutes even though the preinjection level was reached in 95 minutes. Hence, in all of the patients with portal cirrhosis, plasma amino acid retention was noted.

In a group of 6 patients with hepatomegaly of other etiology than cirrhosis, plasma amino acid retention was shown in 2 instances, Table II. In one case of subsiding acute catarrhal jaundice, J. J., the retention was minimal and in one case of glycogen storage disease, T. S., there was moderate retention. To facilitate comparison, other conventional liver function tests are presented in the table. For the sake of brevity, the data are interpreted in qualitative terms.

\section{Results in patients with nephrosis and good renal function}

Nine patients with nephrosis were studied in a similar fashion. With 4 of these patients, one or more curves were repeated at intervals as the opportunity presented itself. Figure 2 shows the amino acid loading curves on patient $C$. C. in the active stage of nephrosis. This patient had moderate edema, the serum albumin was 2 grams per $100 \mathrm{cc}$. and kidney function, as determined by the concentration test and by urea clearance, was normal. Four curves made during a period of 2 months were almost identical, and in all, the plasma amino acid level had returned to the original level within 95 minutes.

Another patient with nephrosis, R. F., had more extensive edema, a serum albumin of 1.6 grams per $100 \mathrm{cc}$., and a urea clearance of 113 per cent of the normal when the studies were begun. The complete data from this patient are included in Table I. He was under observation for one year, without remission of his disease, during which the clinical course was progressively downhill. The serum albumin fell to 1.1 grams per 100 cc., edema increased, and renal function suffered progressive impairment. The urea clearance at the end of the year had fallen to 45 per cent of normal. No enlargement of the liver was noted. During the year, 8 amino acid loading curves were made. All were within normal limits and at no time was retention of plasma amino acids found, in spite of the moderately severe

TABLE II

Results of various liver function tests in patients with hepatomegaly. The quantitative tests are interpreted in a qualitative fashion and + to ++++ indicates deviation from the normal

\begin{tabular}{|c|c|c|c|c|c|c|c|c|c|c|}
\hline & \multicolumn{10}{|c|}{ Liver funotion tects } \\
\hline & D. T. & R. $\mathbf{H}$. & T. M. & E. M. B. & 8. A. & F. B. & J. J. & F. T. & T. 8. & W. M. \\
\hline $\begin{array}{l}\text { Diagnodis } \\
\text { Bromsulfalein } \\
\text { Galactose tolerance } \\
\text { Cholesterol ratio } \\
\text { Bilirubin clearance } \\
\text { Conjugation } \\
\text { Amino acid retention } \\
\text { Berum albumin } \\
\text { Berum globulin } \\
\text { Berum bilirubin }\end{array}$ & $\begin{array}{l}\text { Cirrhosis } \\
\\
++++ \\
+++t \\
\pm \\
+ \\
\text { Normal } \\
+++t \\
3.97 \\
3.17 \\
0.78\end{array}$ & $\begin{array}{l}\text { Cirrhosis } \\
++++ \\
\text { 土 } \\
\text { Normal } \\
\pm \\
+++ \\
+++ \\
2.68 \\
2.61 \\
0.60\end{array}$ & $\begin{array}{c}\text { Cirrhosis } \\
\\
+++ \\
++++ \\
\pm \\
+++ \\
3.46 \\
1.87 \\
0.82\end{array}$ & $\begin{array}{c}\text { Cirrhodis } \\
\\
\text { Normal } \\
\text { Normal } \\
\text { Normal } \\
\pm \\
+++ \\
+ \\
4.58 \\
2.15 \\
0.52\end{array}$ & $\begin{array}{c}\text { Hepato- } \\
\text { megaly } \\
++++ \\
+++t \\
\text { Normal } \\
+++t \\
\text { Normal } \\
4.16 \\
4.68 \\
5.88\end{array}$ & $\begin{array}{c}\text { Hepato- } \\
\text { spleno- } \\
\text { megaly } \\
++++ \\
++ \\
++ \\
++++ \\
\text { Normal } \\
4.88 \\
2.23 \\
5.56\end{array}$ & $\begin{array}{c}\text { Catarrhal } \\
\text { janndice } \\
+ \\
+ \\
\\
\text { Normal } \\
+ \\
4.70 \\
2.41\end{array}$ & $\begin{array}{c}\text { Diabetea; ho- } \\
\text { patomegaly } \\
\text { Normal } \\
\text { Normal } \\
\\
\text { Normal } \\
4.21 \\
2.55 \\
1.01\end{array}$ & $\begin{array}{c}\text { Glycogen } \\
\text { storage } \\
\text { disease } \\
\text { Normal } \\
\text { +t+t } \\
\text { Normal } \\
\\
4 \\
\mathbf{4 . 5 0} \\
\mathbf{8 . 0 5} \\
\mathbf{0 . 5 0}\end{array}$ & $\begin{array}{c}\begin{array}{c}\text { Glycogen } \\
\text { storage } \\
\text { disease }\end{array} \\
\text { Normal } \\
++++ \\
\\
\text { Normal } \\
4.27 \\
2.37\end{array}$ \\
\hline
\end{tabular}




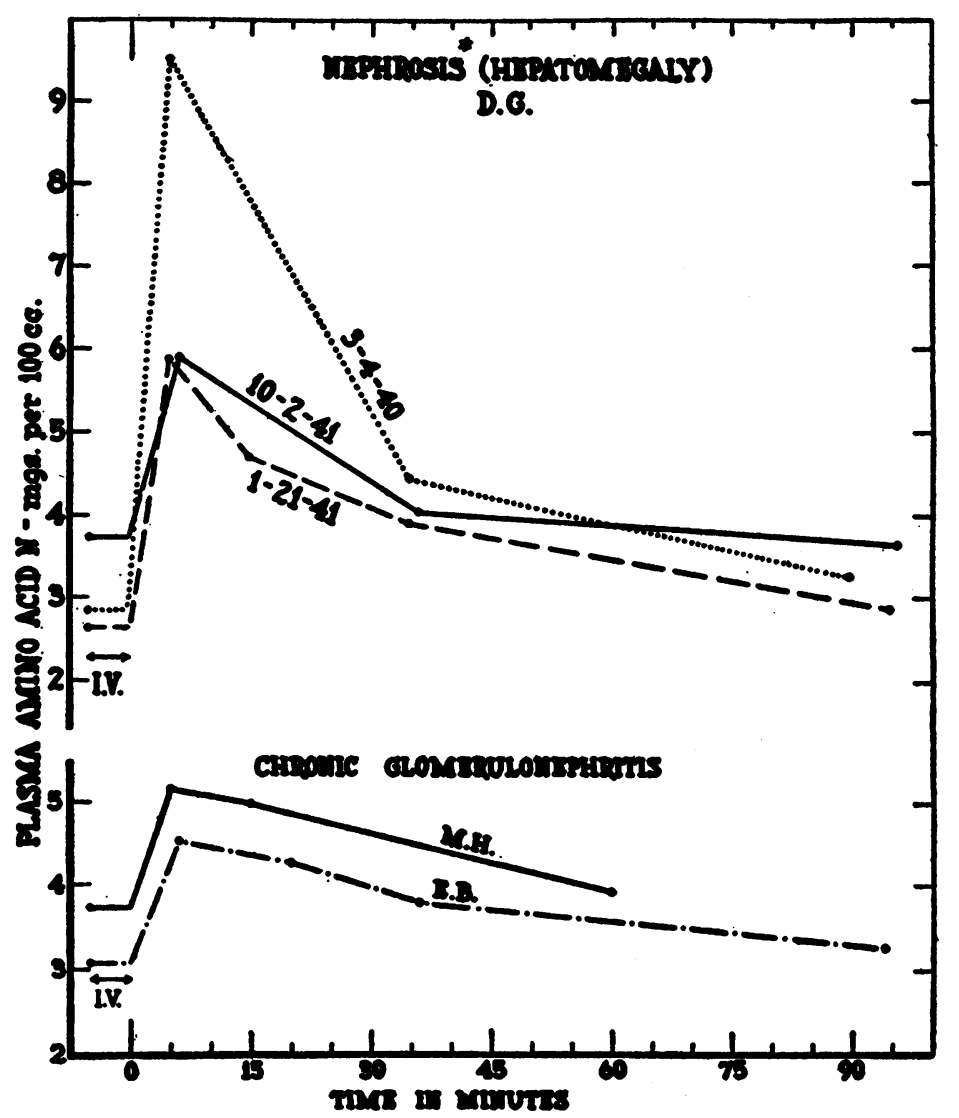

Fig. 3. Behatior of Plasma Amino Actd N Before and After the Injection of Casein Hydrolysate in Patients with Impaired Renal Function

impairment of kidney function. Here again it was possible to duplicate the curve repeatedly during a period of 12 months and the type of curve was similar to those found in the control group (Table I). Curves on 6 other nephrotic patients likewise showed no significant difference from those obtained in the controls. The only exception observed was in patient J. S. in whom slight plasma amino acid retention at 95 minutes was observed on one occasion and was not present later in the course of his disease. We can conclude from these somewhat limited studies that the nephrotic child handles an intravenous load of amino acids in approximately the same manner as a normal child.

\section{Results in patients with kidney disease and impaired renal function}

A few tests were carried out on 2 patients with chronic glomerulonephritis. Both children had been under close observation for many years. Neither had ever developed a nephrotic component of the disease, i.e., massive edema or low serum proteins with a reversal of the albumin/ globulin ratio. In $\mathrm{M}$. $\mathrm{H}$., the urea clearance had fallen to 14 per cent, in E. B., to 35 per cent of the normal. No enlargement of the liver was evident on clinical examination in either patient. The amino acid loading curves shown in Figure 3 did not deviate significantly from the curves obtained in normal children, which suggests that severe kidney injury causes no delay in the clearance of amino acids from the blood stream after an intravenous load.

Patient D. G..$^{B}$ was first seen on January 13,

5 Whether pure nephrosis exists or is a form of glomerulonephritis is an unsettled question and need not concern us here. To the writers, nephrosis is a distinct entity. A certain number of children with nephrosis have clinical glomerulonephritis superimposed, yet not 
1939, with all the findings indicative of pure nephrosis. During the first year, he had numerous severe infections, namely, 6 episodes of bacteremia and 3 attacks of peritonitis, proven by bacterial cultures, from which he recovered with relatively short periods of chemotherapy. After 6 months of observation, hematuria appeared and nitrogen retention developed and persisted, the blood urea $\mathrm{N}$ being as high as $66 \mathrm{mgm}$. per 100 cc. It was thought that glomerular nephritis had been superimposed on the nephrosis. Marked hepatomegaly and splenomegaly developed. The etiology of the hepatomegaly was not clear but one may speculate that lipoid deposition, circulatory difficulties, and infection, all took part. The first loading curve was made on March 4, 1940, when hepatomegaly was present (Table I and Figure 3 ). The liver edge was palpated 5 $\mathrm{cm}$. below the costal margin and the spleen, $4 \mathrm{~cm}$. By this time, the blood urea $\mathrm{N}$ had fallen to 23 mgm. per $100 \mathrm{cc}$, and the urea clearance was 62 per cent of the normal. Serum albumin was recorded as 1.03 grams per $100 \mathrm{cc}$., and massive edema was present. As Figure 3 shows, the fasting plasma amino acid $\mathrm{N}$ was low in the nephrotic range. Following the injection, the plasma amino acid $\mathrm{N}$ rose sharply to $9.6 \mathrm{mgm}$. per 100 cc., a level much higher than had occurred in any control, and at 95 minutes, some retention persisted. Ten months later, on January 21, 1941, a second curve was made. Clinically, the child had had no severe infections since December 8, 1939, and had been free from edema since March 19, 1940. The liver edge could be palpated $2 \mathrm{~cm}$. below the costal margin, the spleen, $1 \mathrm{~cm}$., and kidney function had not changed. Serum albumin had risen to 4.42 grams per $100 \mathrm{cc}$. The fasting plasma amino acid $\mathrm{N}$ value was still low, but the rise following injection was less marked than that shown on the first curve and the final retention was about the same. Ten months after the second curve, October 2, 1941, the liver and spleen were barely palpable and physical examination indicated clinical recovery. However, the blood urea $\mathrm{N}$ remained slightly

all of these patients die in uremia. Some heal completely and remain healed, an outcome which is not compatible with a diagnosis of true chronic glomerulonephritis. A few die in uremia with anatomical findings characteristic of chronic glomerulonephritis. elevated, at $27.4 \mathrm{mgm}$. per $100 \mathrm{cc}$., and the urea clearance was still only 61 per cent of normal. At this time, the fasting plasma amino acid $\mathrm{N}$ level was within normal limits and the loading curve was likewise normal. In this patient, the plasma amino acid $\mathrm{N}$ retention seemed to be correlated more closely with hepatomegaly and possible liver dysfunction than with renal impairment.

\section{Results in patients with nephrocalcinosis}

In 2 patients with nephrocalcinosis, without clinical evidence of hepatic disease, the amino acid loading curves were normal. In one of these patients, the urea clearance indicated moderate impairment, in the other, renal function was good (Table I).

\section{B. URINARY EXCRETION STUDIES}

In addition to the determination of the plasma amino acid $\mathrm{N}$ levels following the intravenous injection of casein hydrolysate, the urinary excretion of the end products of its metabolism was studied in some of the patients, to obtain, if possible, an insight into the rate of deamination. The data obtained enabled estimations to be made of the effect of injections of casein hydrolysate on renal urea and amino acid clearances as well. Pertinent results are presented in Table III.

Certain features were similar in all of the children examined, including the controls. No significant increase in urea clearance was observed following the injection. Only small amounts of amino acid were excreted so that the renal amino acid clearance remained minimal. The ratio of $\left(\mathrm{NH}_{8} \mathrm{~N}+\right.$ urea $\left.\mathrm{N}\right)$ to total N.P.N. remained constant before and after the injection, so it was inferred that the casein hydrolysate was utilized as a metabolic protein.

\section{Results in normal children}

In 4 of the normal controls, urinary studies were carried out. In 3 of these children, during the period of observation following the injection of casein hydrolysate, the rate of ammonia and urea excretion was doubled. In one other control, during forced diuresis with a urine volume of 6 to $7 \mathrm{cc}$. per minute, the increase in ammonia and urea per hour was slight (11). In this patient, it is possible that the transient oliguria (a de- 


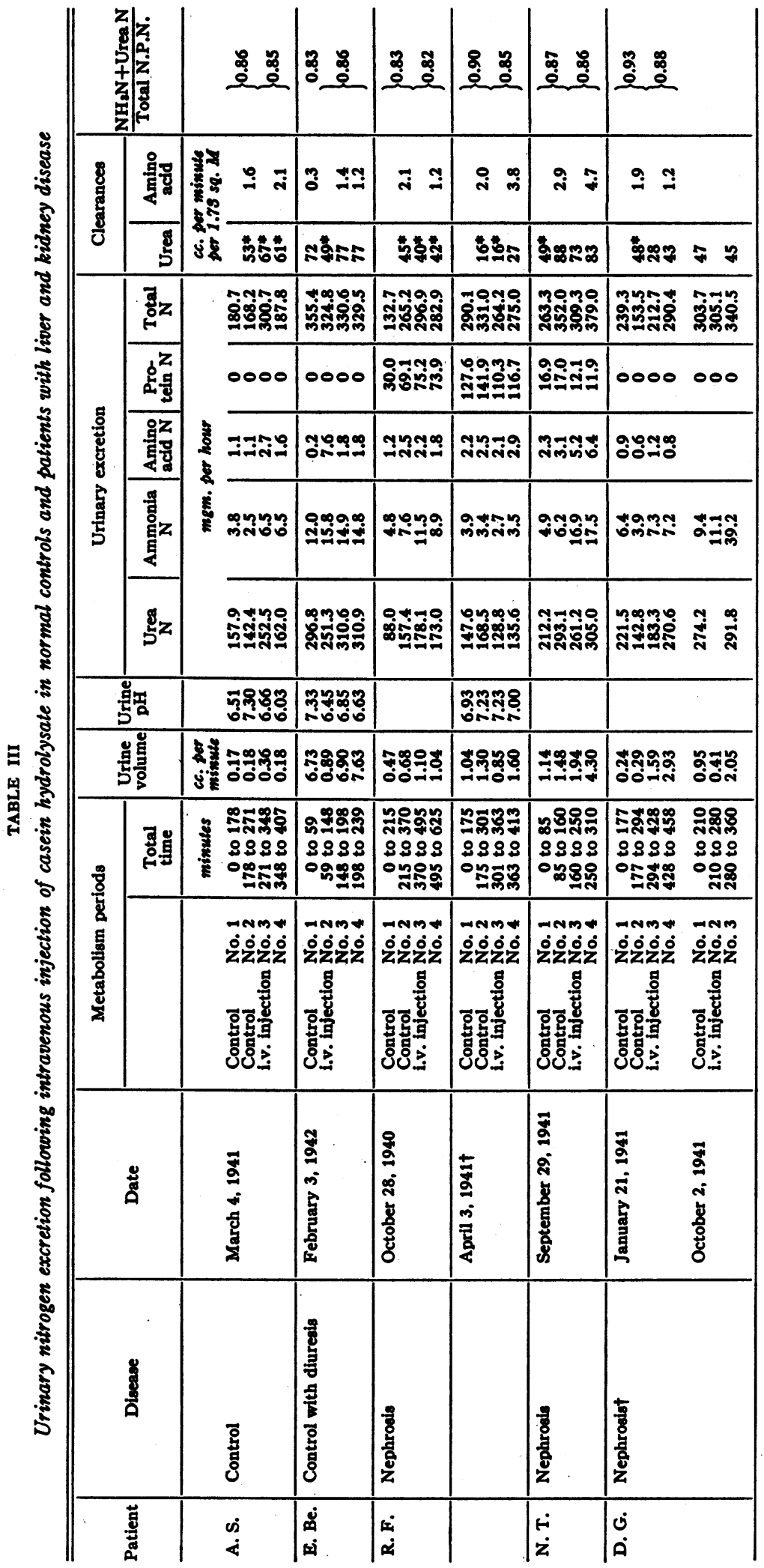


PLASMA AMINO ACID RETENTION

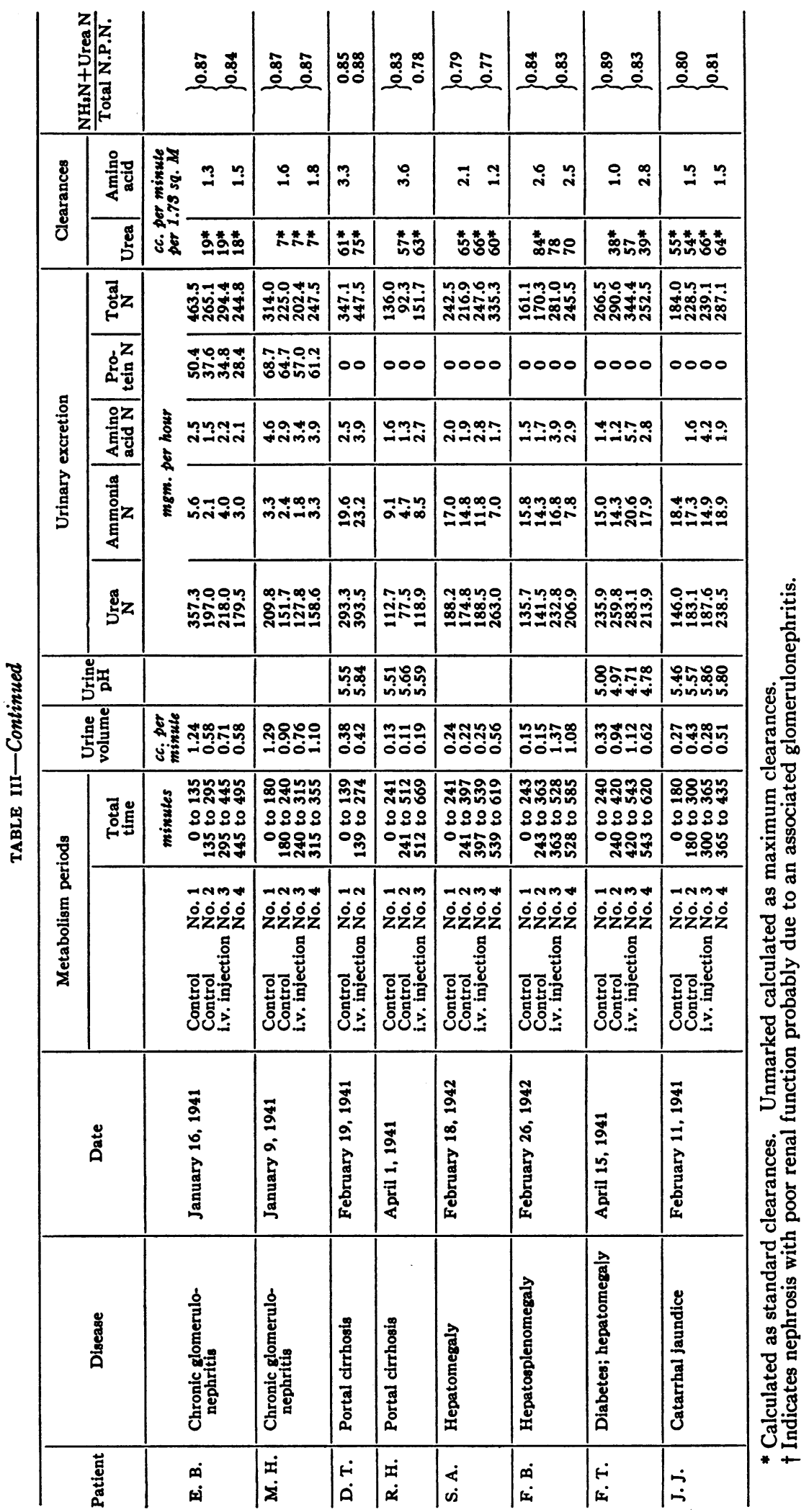


crease in volume from 6 to $7 \mathrm{cc}$ to $0.9 \mathrm{cc}$. per minute) which resulted from the injection of casein hydrolysate masked the findings.

\section{Results in patients with kidney disease}

Four patients with nephrosis in whom kidney function was normal were studied. As in the normal controls, the rate of ammonia excretion was increased two- or threefold but, in contrast to the controls, only a slight increase in the rate of urea excretion was observed.

The manner in which one patient with nephrosis, R. F., metabolized the casein hydrolysate was studied repeatedly. The data from 2 of the studies appear in Table III. As previously described, urinary studies carried out on October 28, 1940, when renal function was good, demonstrated a twofold increase in the rate of ammonia excretion and a slight increase in urea excretion per unit of time. On April 3, 1941, the study was repeated. The clinical course was progressively downhill and at this time, the urea clearance had decreased to 31 per cent of the normal. Following the injection of casein hydrolysate, there was no increase in the amount of ammonia excreted in unit time, while the rate of urea excretion actually diminished. These results were confirmed on 2 subsequent occasions. Thus, this patient when first studied was able to respond to the injection of casein hydrolysate with an increased rate in the excretion of ammonia. Later, as might be expected with diminished kidney function, this ability was lost.

In 2 patients, E. B. and M. H., with chronic glomerulonephritis and severely impaired renal function, with clearances of 35 per cent and 14 per cent of the normal, respectively, as might be predicted, no increase in the rate of ammonia or urea excretion was noted following the injection of casein hydrolysate.

\section{Results in patients with liver disease and good renal function}

Two patients with portal cirrhosis and plasma amino acid retention were available for urinary studies. Before hypoproteinemia had developed, patient $D$. $T$. showed a moderate increase in the rate of urea and ammonia excretion after the injection of casein hydrolysate. In patient $R$. $H$., with severe hypoproteinemia in the later stages of cirrhosis, only a slight increase in the rate of urea and ammonia excretion was observed, which suggested a reduction of deamination.

In patient, J. J., with catarrhal jaundice, in whom moderate plasma amino acid retention had been observed, there was no increase in the rate of ammonia excretion and a considerable lag in the rate of urea excretion. In 2 jaundiced patients, S. A. and F. B., with hepatomegaly of unknown origin, in whom no plasma retention had occurred, a lag in the rate of urea excretion was noted in one but not in the other. In neither patient was there an increase in the rate of ammonia excretion. Thus, 3 jaundiced patients with greatly enlarged livers and no disease of the kidney failed to show any increase in the rate of ammonia excretion above the catabolic level. The data from 2 of these patients suggested a reduction in the rate of deamination; but in only one, J. J., was plasma amino acid retention found.

In patient $F$. $T$., with marked hepatomegaly associated with poorly regulated diabetes, in whom the conventional liver function tests were normal, the rates of ammonia and urea excretion were moderately increased.

\section{DISCUSSION}

A common denominator between the experimental dog and the nephrotic patient is hypoproteinemia, even though the etiology of the hypoalbuminemia is not the same. The nephrotic child remains in positive nitrogen balance when fed protein but is unable to replenish his depleted serum proteins (12), while the experimental dog, with intact ability to generate serum proteins, fails to do so because protein is withheld from the diet. It is commonly assumed that the liver is an essential organ for the synthesis of serum proteins. Since the nephrotic patient can maintain neither adequate serum proteins nor normal plasma amino acid $\mathrm{N}$ levels, it seemed logical to study the metabolism of amino acids in these patients with a view to uncovering possible liver dysfunction.

The manner in which normal children handle an intravenous load of casein hydrolysate was determined. Most of the injected amino acid was removed from the blood stream immediately by diffusion into the tissues, the plasma amino acid $\mathrm{N}$ rose to twice the normal level 5 minutes after 
completion of the injection, and within 95 minutes, the preinjection level was regained in all patients. Loading curves in the nephrotic patients were similar to those obtained in the normal controls.

In contrast, loading curves in 4 patients with portal cirrhosis showed plasma amino acid retention. In 2 patients, hypoalbuminemia was present. In 3, most of the conventional liver function tests indicated severe impairment; in one patient with minimal retention, seen early in the course of the disease, most of the conventional tests were still normal. All of the patients had normal kidney function. In other words, no plasma amino acid retention was found in the normal dog, the normal child, or the hypoproteinemic child with pure nephrosis; while retention was observed in the hypoproteinemic dog with liver injury and in the patients with portal cirrhosis.

In the children with kidney disease and no clinical evidence of liver disease, the loading curves showed no plasma amino acid retention. Hence, it seemed that kidney impairment, even of severe degree, did not interfere with the removal of plasma amino acid when a load was placed on the mechanism. Of passing interest was the fact that the patient with renal glycosuria did not excrete significantly larger amounts of amino acid than the normal controls or other patients.

In the group of patients with hepatomegaly, retention of plasma amino acid following an injection of casein hydrolysate could not be correlated with other tests of liver function to the same degree as in the patients with liver cirrhosis, nor did the additional test of ability to dispose of a load of intravenous amino acids offer a solution to those in search of an infallible test of liver impairment. Actually, the numerous functions of the liver may be selectively impaired as are the functions of the kidney.

In one patient with hepatosplenomegaly and kidney impairment, moderate plasma amino acid retention was found when the liver and spleen were enlarged and disappeared as recovery ensued, even though some impairment of kidney function persisted. In contrast, in chronic glomerulonephritis with severely impaired renal function without liver involvement, no tendency to retention was observed.

In the hypoproteinemic dog, studies of urinary excretion of ammonia, urea, and amino acid, fol- lowing an intravenous injection of casein hydrolystate under standard conditions, suggested that the plasma amino acid retention was probably due largely to a reduction in the rate of deamination.

In the normal child, following intravenous injection of $12 \mathrm{mgm}$. amino acid $\mathrm{N}$ per kilo, the forces of diffusion into the tissues and deamination were such that the preinjection plasma amino acid $\mathrm{N}$ level was reached between 35 and 95 minutes. Most of the amino acid diffused rapidly into all of the tissues and subsequently reached the liver where it was rapidly deaminized to form ammonia, which in turn was synthesized to urea. ${ }^{\circ}$ At normal urine flows in 3 control children, the rates of ammonia and urea excretion per hour were doubled within the period of observation following the injection. Loss of amino acid through the kidney during the injection was minimal. During the period of observation, blood urea levels did not vary significantly, which indicated that the equilibratory mechanism for maintenance of normal blood urea values was not strained by the amount of amino acid given. The observed increase in the rates of ammonia and urea excretion, above the level of catabolism in the absence of acidosis, was considered to represent the balanced response of a normal liver and normal kidneys, in a child, to the injection of $12 \mathrm{mgm}$. of amino acid $\mathrm{N}$ per kilo.

Interpretation of the metabolism studies in the patients was more difficult than in the experimental dog. In the normal dog, the substantial increase in the rate of urea excretion above the catabolic level, immediately following an injection of amino acid, was considered an indication of the speed of deamination. As hypoproteinemia was induced, the decrease in the rate of urea excretion was thought to represent (a) immediate utilization of amino acids to replenish depleted tissues, and (b) a decreased rate of deamination of the remaining fraction which in spite of $(a)$ was sufficient to produce plasma amino acid retention. In the experimental dog, presumably no serious interference with kidney function had occurred,

6 At the present time, it is commonly accepted that practically all deamination occurs in the liver unless base depletion creates an unusual demand for ammonia formation by the kidney (13 to 15$)$. If renal deamination occurs, the chances on the basis of organ size indicate that it will prove to be of relatively small quantitative importance (1). 
since the urea clearance did not vary significantly throughout the period of deproteinization and was only slightly lower than when the dog was fed protein (7); the urine remained normal to microscopic examination throughout the course; and no evidence of morphological injury to the kidney was found post mortem. Obviously, in patients with impaired renal function, the rate of urea excretion could not be used to estimate the speed of deamination. Hence, evaluation of interference with deamination could be attempted only in those patients with good renal function. In the series reported here, this was limited to patients with pure nephrosis and liver disease.

In 4 patients with nephrosis and no plasma amino acid retention, in whom urinary studies were made, the rate of urea excretion was slightly increased, but much less so than in the normal controls. This may be interpreted as a slight reduction in deamination, but it is clear that if reduction in deamination occurred, it was not sufficient to result in plasma amino acid retention.

In only one of 2 patients with portal cirrhosis, in whom urinary studies were made, did the failure to excrete urea above the catabolic level suggest a reduction in deamination. In 2 out of 3 jaundiced patients, there was a lag in the urea excretion suggesting delay in deamination but in only one of them was plasma amino acid retention observed. Although urinary studies in patients with hepatomegaly in whom plasma amino acid retention was observed were too limited in number to permit a definite conclusion, the data obtained are compatible with the suggestion that deamination is delayed.

Nash and Benedict in 1921 (16) proved by a series of ingenious experiments that urinary ammonia is formed only in the kidney. Bliss (17) demonstrated that certain amino acids can serve as the precursors for ammonia formation in the kidney of acidotic dogs. The subject of ammonia formation and transport in the blood stream is still controversial and has been reviewed recently $(1,18,19)$. The data obtained in normal children and in patients with kidney disease are compatible with the theory of ammonia formation proposed by Nash and Benedict. In contrast, the patients with liver disease and unimpaired kidney function, as judged by urea clearance, failed to excrete ammonia at the expected rate, even though an acidosis was present. Present knowledge offers no satisfactory explanation of the observed fact.

\section{SUMMARY}

In 45 normal hospital children, the fasting plasma amino acid $\mathrm{N}$ ranged from 2.92 to 4.63 mgm. per $100 \mathrm{cc}$.

Intravenous injections of casein hydrolysate were given to normal children, and to patients with nephrosis, nephritis, and liver disease. In 4 children with portal cirrhosis, a delay in clearing the plasma of amino acids was observed following the injection. In 2 of 7 patients with liver disease other than cirrhosis, a moderate delay was noted. In one patient with hepatosplenomegaly and impaired renal function, retention of plasma amino acid was noted, which disappeared when the enlargement of liver and spleen abated.

On the other hand, 8 of 9 patients with nephrosis, 2 patients with chronic glomerular nephritis, and 3 patients with various other types of kidney disease cleared the plasma of amino acid as quickly as the normal controls. Severe impairment of renal function offered no obstacle to the rapid clearing of injected amino acid from the plasma, while delay in plasma clearance could be related to liver dysfunction.

Urinary excretion studies were carried out in some of the patients following the injection. Representative patients of each of the above groups showed no significant increase in urea clearance. Only small amounts of amino acid were excreted so that the amino acid clearance was low, a few cc. per minute per sq. $M$.

The rate of urea excretion in nephrotic and cirrhotic patients and in those with other forms of liver disease, although increased slightly above the catabolic level, was not so great as that observed in the controls. This might indicate a reduction in deamination.

The rate of ammonia excretion in normal controls and in patients with nephrosis was doubled immediately after the injection. In 5 patients with severe impairment of renal function, no increase in the rate of ammonia excretion was noted. Although 2 patients with cirrhosis showed a slight increase in ammonia excretion, 3 jaundiced patients with marked hepatomegaly and normal renal function failed to excrete ammonia above the catabolic level. 


\section{BIBLIOGRAPHY}

1. Kirk, E., Amino acid and ammonia metabolism in liver diseases. Acta med. Scandinav., 1936, supp. $77,1$.

2. Kitamura, I., On behavior of liver with reference to metabolism of amino-acids; loading experiments of various amino acids in normal rabbits, in rabbits with injured liver and in rabbits whose kidneys are extirpated. Jap. J. Gastroenterol., 1937, 9, 166.

3. Horejsi, J., Mecl, A., and Spisarova, J., The metabolism of amino acids and liver functions. Acta. med. Scandinav., 1938, 96, 217.

4. Weicker, B., Uber den Nachweis gestörter Teilfunktionen als Grundlage funktioneller Leberdiagnostik. Ztschr. f. d. ges. exper. Med., 1932, 81, 481.

5. Weech, A. A., Puzzles of protein privation. J. Pediat., 1941, 19, 608.

6. Elman, R., and Heifetz, C. J., Experimental hypoalbuminemia; its effect on the morphology, function, and protein and water content of the liver. J. Exper. Med., 1941, 73, 417.

7. Goettsch, E., Lyttle, J. D., Grim, W. M., and Dunbar, P., Amino acid studies. I. Plasma amino acid retention in the hypoproteinemic dog as evidence of impaired liver function. J. Biol. Chem., 1942, 144, 121.

8. Farr, L. E., and MacFadyen, D. A., Hypoaminoacidemia in children with nephrotic crises. Am. J. Dis. Child., 1940, 59, 782.

9. Farr, L. E., McCarthy, W. C., and Francis, T., Plasma amino acid levels in health and in measles, scarlet fever and pneumonia. Am. J. M. Sc., 1942, 203, 668.

10. Van Slyke, D. D., Dillon, R. T., MacFadyen, D. A., and Hamilton, P., Gasometric determination of carboxyl groups in free amino acids. J. Biol. Chem., 1941, 141, 627. The application of the method to plasma and urine is in preparation.

11. Peters, J. P., and Van Slyke, D. D., Quantitative Clinical Chemistry. The Williams and Wilkins Company, Baltimore, 1931. Vol. I-Interpretations, p. 344.

12. Farr, L. E., The intravenous administration of small doses of casein hydrolysate to nephrotic children and its effect upon the nitrogen balance and plasma amino acid level. J. Pediat., 1940, 16, 679.

13. Van Slyke, D. D., Cullen, G. E., and McLean, F. C., The formation of urea in the liver. Proc. Soc. Exper. Biol. and Med., 1915, 12, 93.

14. Van Slyke, D. D., and Meyer, G. M., The fate of protein digestion products in the body. IV. The locus of chemical transformation of absorbed amino acids. J. Biol. Chem., 1913-14, 16, 213.

15. Bollman, J. L., Mann, F. C., and Magath, T. B., Studies in physiology of the liver. VIII. Effect of total removal of the liver on formation of urea. Am. J. Physiol., 1924, 69, 371.

16. Nash, T. P., Jr., and Benedict, S. R., Ammonia content of the blood, and its bearing on the mechanism of acid neutralization in the animal organism. J. Biol. Chem., 1921, 48, 463.

17. Bliss, S., Increased excretion of urinary ammonia in dog following intravenous injection of both natural and unnatural forms of certain amino acids. J. Biol. Chem., 1941, 137, 217.

18. Smith, H. W., The Physiology of the Kidney. Oxford University Press, New York, 1937, p. 179.

19. Friedenson, M., On the origin of ammonia in urine under normal circumstances and in kidney disease. Am. J. M. Sc., 1939, 198, 546. 